\title{
A single-center, randomized, parallel controlled study comparing the efficacy and safety aspects of three anthracycline-based regimens as neoadjuvant chemotherapy in primary breast cancer
}

\author{
Yijun Zhou $^{1} \cdot$ Tao Ouyang ${ }^{1} \cdot$ Yuntao Xie $^{1} \cdot$ Tianfeng Wang $^{1} \cdot$ Zhaoqing Fan $^{1} \cdot$ \\ Yingjian $\mathrm{He}^{1} \cdot$ Aiping $\mathrm{Lu}^{2} \cdot$ Yiqiang $\mathrm{Liu}^{2} \cdot$ Jinfeng $\mathrm{Li}^{1}$
}

Received: 20 March 2016/Accepted: 22 May 2016/Published online: 1 June 2016

(c) The Author(s) 2016. This article is published with open access at Springerlink.com

\begin{abstract}
This study aimed to compare the efficacy and safety aspects of three anthracycline-based regimens as neoadjuvant chemotherapy in primary breast cancer. Fivehundred and one patients with clinical stage I-III invasive breast cancer were randomly assigned to receive four cycles of neoadjuvant chemotherapy with either CEFci arm (5-Fu $200 \mathrm{mg} / \mathrm{m}^{2}$ daily by $24-\mathrm{h}$ continuous infusion and epirubicin $100 \mathrm{mg} / \mathrm{m}^{2}$ and cyclophosphamide $600 \mathrm{mg} / \mathrm{m}^{2}$ intravenous bolus on day 1), CEF arm (cyclophosphamide $600 \mathrm{mg} / \mathrm{m}^{2}$, epirubicin $100 \mathrm{mg} / \mathrm{m}^{2}$, and $5-\mathrm{Fu} 600 \mathrm{mg} / \mathrm{m}^{2}$ i.v. on day 1), or EC arm (epirubicin $100 \mathrm{mg} / \mathrm{m}^{2}$ and cyclophosphamide $600 \mathrm{mg} / \mathrm{m}^{2}$ i.v. on day 1). The pathologic responses to chemotherapy were assessed according to the Miller and Payne grading system (MP). A total of 485 patients were included in the intent-to-treat population. Breast pathologic complete response (pCR) rate was $18.9 \%(31 / 164)$ in CEFci arm, $15.0 \%$ (24/160) in CEF arm, and $12.4 \%(20 / 161)$ in EC arm $(P=0.266)$. MP grading system $4 / 5$ response rate was significantly higher in CEFci arm than that in CEF arm and EC arm (44.5, 31.3 and $27.3 \%$, respectively, $P=0.003)$. There was no significant difference on grade III/IV neutropenia among three arms $(P=0.538)$, but thrombocytopenia, decreased hemoglobin, and elevated aminotransferase appeared to be
\end{abstract}

Jinfeng Li

jinfeng_li@hotmail.com

1 Breast Center, Key Laboratory of Carcinogenesis and Translational Research (Ministry of Education), Peking University Cancer Hospital \& Institute, Beijing 100142, China

2 Department of Pathology, Key Laboratory of Carcinogenesis and Translational Research (Ministry of Education), Peking University Cancer Hospital \& Institute, Beijing 100142, China observed more in CEFci arm $(P=0.040,0.059$, and 0.073, respectively). CEFci did not reach a higher pCR rate compared with CEF or EC in patients with primary breast cancer. The potential advantage of CEFci in improving pathologic response still requires further research. The accompanied hematologic and biochemical toxicities, and the catheter-related complications should also be noted.

Keywords Breast cancer - 5-Fluorouracil · Neoadjuvant chemotherapy · Pathologic complete response

\section{Introduction}

Neoadjuvant chemotherapy is the standard treatment for locally advanced and inflammatory breast cancer and is applied to downstage tumors initially not suitable for resection or breast-conserving surgery [1,2]. Moreover, the application of neoadjuvant chemotherapy in operable breast cancer is gradually increasing because of the advantages of using the tumor as an early in vivo measure of response to treatment [3]. Previous studies showed that tumor response to neoadjuvant chemotherapy was associated with prognosis of breast cancer patients, and those who achieved the pathologic complete response (pCR) potentially obtain better survival $[4,5]$. Currently, anthracycline-based polychemotherapy regimens are frequently used in the adjuvant treatment in breast cancer, and 5-fluorouracil (5-Fu) is also commonly included [6-8]. In contrast with intravenous bolus 5 -Fu, continuous infusion of 5-Fu showed a more significant efficacy and less adverse reactions with a relatively short half-life $(<30 \mathrm{~min})[9,10]$. In order to search for a more effective regimen of 5 -Fu combined with epirubicin and cyclophosphamide, we designed a single-center, randomized, parallel controlled 
study to compare the efficacy and safety aspects of three different regimens: cyclophosphamide/epirubicin/intravenous bolus 5-Fu (CEF), cyclophosphamide/epirubicin/ continuous infusional 5-Fu (CEFci), and cyclophosphami de/epirubicin (EC) with absence of 5-Fu.

\section{Methods}

\section{Patients}

We included in the study female clinical stage I-III $\left(\mathrm{cT}_{1-3} \mathrm{~N}_{0-2} \mathrm{M}_{0}\right)$ breast cancer patients aged $\leq 65$ years old with histologically confirmed invasive breast cancer by core needle biopsy in our breast center from March 2011 to July 2014. All subtypes defined by immunohistochemistry hormone receptor (HR) and human epidermal growth factor receptor 2 (HER2) status were enrolled in the study, including HR-positive and HER2-negative subtype (HR+HER2-), triple-negative subtype (HR-HER2-), and HER2-positive subtype (HER2+). Further relevant eligibility criteria included no history of other malignancies; adequate hematologic function (absolute neutrophils count $\geq 1.5 \times 10^{9} / \mathrm{L}$, platelets $\geq 100 \times 10^{9} / \mathrm{L}$, and hemoglobin $\geq 100 \mathrm{~g} / \mathrm{L}$ ); adequate hepatic and renal functions [alanine aminotransferase (ALT)/aspartate aminotransferase (AST) $\leq 2.5$ times the institutional upper normal limit (UNL), serum bilirubin $\leq 1.5 \times \mathrm{UNL}$, and serum creatinine $\leq 1.7 \mathrm{mg} / \mathrm{dl}]$; and normal cardiac function. Patients with pregnancy or in lactation; with known or suspected distant metastases diagnosed by chest X-ray, abdominal and pelvic ultrasound, or bone scans; or with currently uncontrolled diseases (e.g., cardiac dysrhythmias, unstable diabetes) or active infection were excluded. Patients with the Miller and Payne (MP) grading results were included in the intention-to-treat analyses (ITT), and those without neoadjuvant chemotherapy or without surgery were excluded. All the enrolled patients were provided with written informed consent.

\section{Study design}

This is a single-center, randomized, and parallel controlled study designed to compare the efficacy and safety aspects among three anthracycline-based regimens for neoadjuvant chemotherapy in patients with primary breast cancer, registered with ClinicalTrials.gov, number NCT01199432.

Patients were centrally randomly assigned $(1: 1: 1)$ to receive one of the three neoadjuvant chemotherapy: Arm A: cyclophosphamide, epirubicin, and continuous infusional 5-fluorouracil (CEFci); Arm B: cyclophosphamide, epirubicin, and intravenous bolus 5-fluorouracil (CEF); or Arm C: cyclophosphamide and epirubicin (EC). After completion of four cycles of neoadjuvant chemotherapy, patients underwent surgery and possible following adjuvant treatment (chemotherapy, trastuzumab, radiotherapy, or endocrinotherapy) according to the guidelines of NCCN and St. Gallen [11].

\section{Treatment}

All eligible patients received cyclophosphamide $\left(\mathrm{C}, 600 \mathrm{mg} / \mathrm{m}^{2}\right)$ plus epirubicin $\left(\mathrm{E}, 100 \mathrm{mg} / \mathrm{m}^{2}\right)$ administered as intravenous boluses on day 1 of every 3 weeks. In arm A (CEFci regimen), 5-fluorouracil (5-Fu, $200 \mathrm{mg} / \mathrm{m}^{2}$ ) was administered as a $24-\mathrm{h}$ continuous infusion using an ambulatory pump via Hickman line through a central venous catheter for 12 weeks; in arm B (CEF regimen), 5 -Fu $\left(600 \mathrm{mg} / \mathrm{m}^{2}\right)$ was administered as intravenous bolus on day 1 every 3 weeks; however, in arm C (EC regimen), 5 -Fu was not included.

\section{Toxicity and chemotherapy delay}

Toxicity was assessed according to common toxicity criteria grade by laboratory examination, including routine blood tests on day 7, 10,14, 21 and biochemistry test on day 21 before every next cycle of chemotherapy. Recombinant human granulocyte colony-stimulating factor was applied at $5 \mu \mathrm{g} / \mathrm{kg} / \mathrm{d}$ subcutaneously for three days if leukocyte count $<2.0 \times 10^{9} / \mathrm{L}$ and/or absolute neutrophils count $<1.0 \times 10^{9} / \mathrm{L}$, and antibiotics were prescribed simultaneously for any episode of febrile neutropenia. Recombinant human interleukin-11 support was given at 24 million IU/d subcutaneously for seven days if platelets count $<50 \times 10^{9} / \mathrm{L}$, and liver-protection therapy was conducted if ALT/AST level was found higher than 2.5 times the institutional UNL.

Treatment was delayed for one or two weeks when absolute neutrophils count $<1.5 \times 10^{9} / \mathrm{L}$, platelets count $<100 \times 10^{9} / \mathrm{L}$, hemoglobin count $<80 \mathrm{~g} / \mathrm{L}$, ALT/AST $\geq 2.5 \times \mathrm{UNL}$, and/or when blood urea nitrogen/creatinine was found abnormal during hematologic and biochemical tests on day 21 before every next cycle of chemotherapy. We terminated neoadjuvant chemotherapy if treatment was delayed for more than two weeks, if there was incidence of disease progression or severer adverse events, or according to the patient's wills.

\section{Response assessment}

Tumor clinical response to chemotherapy was both assessed by ultrasonography after completion of the second and the fourth cycles of treatment before surgery using the World Health Organization criteria. Complete response (CR) was defined as complete resolution of all masses and 
abnormalities. Partial response (PR) was defined as a $\geq 50 \%$ reduction in the product of the bidimensional tumor measurements without progression of any lesion or appearance of any new disease. For stable disease (SD), there was a $<50 \%$ reduction or $<25 \%$ increase, whereas for progressive disease (PD), there was a $\geq 25 \%$ increase or appearance of new disease [12].

Tissue slices from core needle biopsy both before neoadjuvant chemotherapy and surgery were collected from the Department of Pathology, and the histologic response to chemotherapy in breast was assessed by two senior pathologists using the Miller and Payne grading system: Grade 1 (G1): no change or some alteration to individual malignant cells but no reduction in overall cellularity; Grade 2 (G2): a minor loss of tumor cells but overall cellularity still high-up to $30 \%$ loss; Grade 3 (G3): between an estimated 30 and $90 \%$ reductions in tumor cells; Grade 4 (G4): a marked disappearance of tumor cells such that only small clusters or widely dispersed individual cells remain-more than $90 \%$ loss of tumor cells; and Grade 5 (G5): no malignant cells identifiable in sections from the site of the tumor-only vascular fibroelastotic stroma remains often containing macrophages. However, ductal carcinoma in situ may be present [13]. Each pathologist scored the tumor tissues independently, and agreement by consensus was achieved if necessary. In this study, we defined grade 5 (G5) as pCR [14].

In this study, the primary end point was pathologic complete response, and the secondary endpoints were MP response, clinical response, and adverse effect.

\section{Sample size calculation and statistics}

Based on an expected rate of pathologic complete response with $10 \%$ in arm $\mathrm{C}$ (EC regimen), $25 \%$ in arm $\mathrm{B}$ (CEF regimen), and $40 \%$ in arm $\mathrm{A}$ (CEFci regimen), 456 patients were calculated as a minimum sample size to provide $80 \%$ power, with $\alpha=0.05$ (two-sided) level of significance to detect an absolute difference in pCR rate in excess of $15 \%$ among arms. With possible follow-up loss of less than $10 \%$ of patients, the total sample size was determined as 501 .

Number or percentage was used to describe categorical variables. The comparison of $\mathrm{pCR}$ rate or clinicopathologic characteristics among the arms was performed with Chi square test or Fisher's exact test. Logistic regression model was carried out to compare the odds ratios (ORs) for pathologic response among the arms in multivariate analyses. All statistical tests were two-sided, and bonferroni correction was used for multiple comparisons. $P$ values $<0.05$ were considered statistically significant.
Sample size calculation and statistical analyses were performed using PASS 2008 software and SPSS 17.0 software, respectively.

\section{Results}

\section{Patients}

Between March 11, 2011 and July 17, 2014, a total of 501 patients (167 assigned to each arm) were enrolled from the Breast Center, Peking University Cancer Hospital. As Table 1 shows, characteristics (including age, menstrual status, tumor size, lymph node status, pathological type, histologic grade, IHC-defined subtype, ki-67 index, and surgery type) were balanced across the three treatment arms. Four (two in arm B and two in arm C) patients were found to be ineligible after randomization, leaving 497 patients in total receiving neoadjuvant chemotherapy. Of the four ineligible patients, three underwent surgery immediately due to uncontrolled hypertension, severe anemia, and thrombocytopenia, respectively, and the remaining one refused any treatment. Twelve (3 in arm A, 5 in $\operatorname{arm~B}$, and 4 in arm C) of 497 patients did not undergo surgery due to their being lost to follow-up, leaving 485 with available pathologic response to chemotherapy in breast for the ITT analyses. Of these 485 patients, the following patients were omitted: 10 (9 in arm A and 1 in arm C) who were against protocols and selected regimens independently after randomization; and 10 (all in arm A) who had terminated continuous infusional 5-fluorouracil through central venous catheters after completion of one cycle of neoadjuvant chemotherapy (six with catheter thrombus, one with catheter infection, and three since they refused). Neoadjuvant chemotherapy was discontinued on 14 patients ( 7 in $\operatorname{arm~A,~} 4$ in $\operatorname{arm~B}$, and 3 in arm C) due to severe adverse events, including febrile neutropenia, hepatic injury, nausea and vomiting, oral ulcer, epilepsy, atrial fibrillation, and palpitation. According to tumor response and/or patient's wills, neoadjuvant treatment was adjusted for surgery, endocrinotherapy, or followed by four cycles of paclitaxel regimen on 28 patients ( 3 in arm A, 12 in arm B, and 13 in arm C) (Fig. 1).

\section{Efficacy}

The primary analyses of tumor response to neoadjuvant chemotherapy were carried out in the intention-to-treat population of 485 patients: $164(33.8 \%)$ in arm A, 160 $(32.9 \%)$ in arm B, and $161(33.2 \%)$ in arm C (Table 2). Of these 485 patients, a total of $75(15.5 \%)$ achieved the pCR in breast, and there were no statistically significant 
Table 1 Characteristics of 501 patients enrolled

\begin{tabular}{|c|c|c|c|}
\hline Characteristics & $\begin{array}{l}\text { Arm A } \\
\text { CEFci } \\
(N=167) \\
N(\%)\end{array}$ & $\begin{array}{l}\text { Arm B } \\
\text { CEF }(N=167) \\
N(\%)\end{array}$ & $\begin{array}{l}\text { Arm C } \\
\mathrm{EC} \\
(N=167) \\
N(\%)\end{array}$ \\
\hline \multicolumn{4}{|l|}{ Age (years) } \\
\hline$>35$ & $152(91.0)$ & $150(89.8)$ & $156(93.4)$ \\
\hline$\leq 35$ & $15(9.0)$ & $17(10.2)$ & $11(6.6)$ \\
\hline \multicolumn{4}{|l|}{ Menstrual status } \\
\hline Postmenopause & $48(28.7)$ & $52(31.1)$ & $67(40.1)$ \\
\hline Premenopause & $119(71.3)$ & $115(68.9)$ & $100(59.9)$ \\
\hline \multicolumn{4}{|l|}{ Tumor size ${ }^{\mathrm{a}}$} \\
\hline$T \leq 2 \mathrm{~cm}$ & $30(18.0)$ & $29(17.4)$ & $28(16.8)$ \\
\hline $2 \mathrm{~cm}<T \leq 5 \mathrm{~cm}$ & $120(71.9)$ & $130(77.8)$ & $130(77.8)$ \\
\hline$T>5 \mathrm{~cm}$ & $17(10.1)$ & $8(4.8)$ & $9(5.4)$ \\
\hline \multicolumn{4}{|l|}{ Lymph node status } \\
\hline Negative & $56(33.5)$ & $46(27.5)$ & $39(23.4)$ \\
\hline Positive & $109(65.3)$ & $116(69.5)$ & $121(72.5)$ \\
\hline Unknown & $2(1.2)$ & $5(3.0)$ & $7(4.2)$ \\
\hline \multicolumn{4}{|l|}{ Pathological type } \\
\hline Invasive ductal carcinoma & $157(94.0)$ & $154(92.2)$ & $154(92.2)$ \\
\hline Others $^{\mathrm{b}}$ & $10(6.0)$ & $13(7.8)$ & $13(7.8)$ \\
\hline \multicolumn{4}{|l|}{ Histologic grade } \\
\hline I & $7(4.2)$ & $10(6.0)$ & $10(6.0)$ \\
\hline II & $110(65.9)$ & $104(62.3)$ & $112(67.0)$ \\
\hline III & $39(23.3)$ & $38(22.7)$ & $30(18.0)$ \\
\hline Unknown & $11(6.6)$ & $15(9.0)$ & $15(9.0)$ \\
\hline \multicolumn{4}{|l|}{ IHC-defined subtype } \\
\hline HR+HER2- & $84(50.2)$ & $88(52.7)$ & $83(49.7)$ \\
\hline HR-HER2- & $40(24.0)$ & $42(25.1)$ & $42(25.1)$ \\
\hline HER2+ & $33(19.8)$ & $26(15.6)$ & $30(18.0)$ \\
\hline Unknown $^{c}$ & $10(6.0)$ & $11(6.6)$ & $12(7.2)$ \\
\hline \multicolumn{4}{|l|}{ Ki-67 index } \\
\hline$\geq 25 \%$ & $100(59.9)$ & $99(59.3)$ & $98(58.7)$ \\
\hline$<25 \%$ & $67(40.1)$ & $68(40.7)$ & $69(41.3)$ \\
\hline \multicolumn{4}{|l|}{ Surgery type } \\
\hline Breast-conserving surgery & $47(28.1)$ & $43(25.7)$ & $41(24.6)$ \\
\hline Mastectomy & $117(70.1)$ & $119(71.3)$ & $121(72.4)$ \\
\hline Unknown & $3(1.8)$ & $5(3.0)$ & $5(3.0)$ \\
\hline \multicolumn{4}{|c|}{ a Measured by ultrasonography } \\
\hline \multicolumn{4}{|c|}{$\begin{array}{l}\text { b Include infiltrating lobular carcinoma, medullary carcinoma, colloid carcinoma, metaplastic carcinoma } \\
\text { neuroendocrine carcinoma, cribriform carcinoma, and micropapillary carcinoma }\end{array}$} \\
\hline \multicolumn{4}{|c|}{ c $I H C$ immunohistochemistry $H R$ hormone receptor $H E R 2$ human epidermal growth factor receptor 2} \\
\hline d No further assessment of & dorescence in & lization (FISH) in & 2+) patients \\
\hline
\end{tabular}

differences in pCR rates among the three arms (18.9 vs. 15.0, and $12.4 \%, P=0.266$ ) (Table 2). The percentages of patients with clinical CR or PR was $63.4 \%(104 / 164)$ in $\operatorname{arm~A,~} 53.8 \%(86 / 160)$ in arm B, and $52.8 \%(85 / 161)$ in arm C, with no statistically significant differences $(P=0.101)$ (Table 2$)$. As Table 3 shows, the percentage of patients with MP 4/5 response in breast was higher in arm A than that in arm B (44.5 vs. $31.3 \%)$ with statistically significant difference $(P=0.004)$, and an OR of 2.081 (95\% CI 1.264-3.427), but the percentage in arm B was similar to that in arm C (31.3 vs. $27.3 \%)$, with no statistically significant difference (OR 0.821, $95 \%$ CI 0.489-1.378, $P=0.455$ ). Besides treatment regimens, pathologic response to neoadjuvant chemotherapy in breast was also associated with tumor size, ki-67 index, and IHCdefined subtype. 


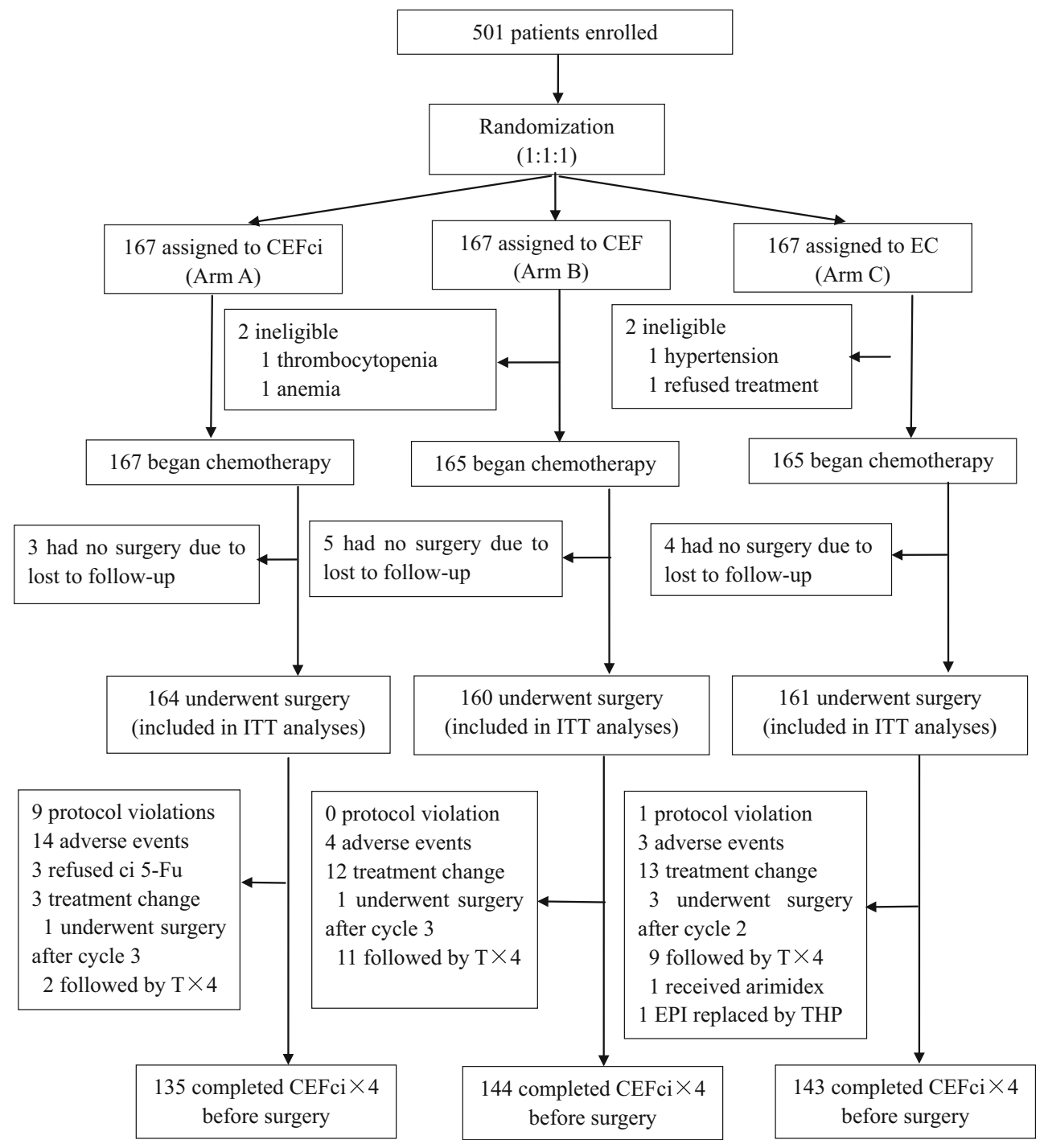

Fig. 1 CONSORT flow diagram. $C$ cyclophosphamide, $E$ epirubicin, $F$ 5-fluorouracil, $c i$ continuous infusion, $I T T$ intention-to-treat, $T$ paclitaxel, $E P I$ epirubicin, THP pirarubicin

Table 2 Pathologic and clinical responses in breast to neoadjuvant chemotherapy

\begin{tabular}{lllll}
\hline Response & $\begin{array}{l}\text { Arm A } \\
\text { CEFci } \\
(N=164)\end{array}$ & $\begin{array}{l}\text { Arm B } \\
\text { CEF } \\
(N=160)\end{array}$ & $\begin{array}{l}\text { Arm C } \\
\text { EC }(N=161)\end{array}$ & $P$ value \\
& $N(\%)$ & & \\
\hline Pathologic complete response (G5) & $31(18.9)$ & $24(15.0)$ & $20(12.4)$ & 0.266 \\
MP4/5 response $(\mathrm{G} 4 / 5)^{\mathrm{a}}$ & $73(44.5)$ & $50(31.3)$ & $44(27.3)$ & 0.003 \\
CR + PR & $104(63.4)$ & $86(53.8)$ & $85(52.8)$ & 0.101 \\
\hline
\end{tabular}

$C R$ complete response $P R$ partial response

${ }^{a}$ Miller and Payne grading system

\section{Hematologic and biochemical toxicity}

The percentages of patients with grade III/IV neutropenia were $80.5 \%(132 / 164)$ in arm A, $74.4 \%(119 / 160)$ in arm $\mathrm{B}$, and $72.0 \%(116 / 161)$ in arm $\mathrm{C}$, respectively, and there was no statistically significant difference among the three groups $(P=0.538) \quad$ (Table 4$)$. Hemoglobin count $\leq$ $109 \mathrm{~g} / \mathrm{L}$ (grade I-IV) was observed in 56 (34.1\%) of 164 patients in arm A, 48 (30.0\%) of 160 patients in arm B, and $36(22.4 \%)$ of 161 patients in arm $\mathrm{C}$, and the 
Table 3 Associations of chemotherapy regimens and tumor characteristics with pathologic response

\begin{tabular}{|c|c|c|c|c|c|c|}
\hline \multirow[t]{2}{*}{ Characteristics } & \multicolumn{2}{|l|}{ Pathologic response } & & \multicolumn{3}{|c|}{ Multivariate analysis } \\
\hline & $\begin{array}{l}\text { G4/G5 }(N=167) \\
N(\%)\end{array}$ & $\begin{array}{l}\mathrm{G} 1 / \mathrm{G} 2 / \mathrm{G} 3(N=318) \\
N(\%)\end{array}$ & & OR & $95 \% \mathrm{CI}$ & $P$ value \\
\hline Age (years) & & & 0.239 & & & \\
\hline$>35$ & $156(35.2)$ & $287(64.8)$ & & 1.331 & $0.600-2.950$ & 0.482 \\
\hline$\leq 35$ & $11(26.2)$ & $31(73.8)$ & & 1 & & \\
\hline Menstrual status & & & 0.044 & & & \\
\hline Postmenopause & $65(40.6)$ & $95(59.4)$ & & 1.359 & $0.862-2.142$ & 0.186 \\
\hline Premenopause & $102(31.4)$ & $223(68.6)$ & & 1 & & \\
\hline Tumor size ${ }^{\mathrm{a}}$ & & & $<0.001$ & & & $<0.001$ \\
\hline$T \leq 2 \mathrm{~cm}$ & $44(52.4)$ & $40(47.6)$ & & 10.415 & $3.244-33.438$ & $<0.001$ \\
\hline $2 \mathrm{~cm}<T \leq 5 \mathrm{~cm}$ & $118(32.0)$ & $251(68.0)$ & & 3.897 & $1.322-11.485$ & 0.014 \\
\hline$T>5 \mathrm{~cm}$ & $5(15.6)$ & $27(84.4)$ & & 1 & & \\
\hline Lymph node status & & & 0.059 & & & 0.261 \\
\hline Unknown & $1(8.3)$ & $11(91.7)$ & & 0.196 & $0.023-1.676$ & 0.137 \\
\hline Positive & $111(33.1)$ & $224(66.9)$ & & 1.126 & $0.695-1.825$ & 0.630 \\
\hline Negative & $55(39.9)$ & $83(60.1)$ & & 1 & & \\
\hline Pathological type & & & 0.342 & & & \\
\hline Invasive ductal arcinoma & $152(33.9)$ & $297(66.1)$ & & 0.563 & $0.261-1.213$ & 0.142 \\
\hline Others $^{\mathrm{b}}$ & $15(41.7)$ & $21(58.3)$ & & 1 & & \\
\hline IHC-defined subtype ${ }^{c}$ & & & $<0.001$ & & & 0.007 \\
\hline Unknown $^{\mathrm{d}}$ & $10(31.3)$ & $22(68.8)$ & & 1.358 & $0.584-3.158$ & 0.478 \\
\hline HR-/HER2- & $56(46.3)$ & $65(53.7)$ & & 1.922 & $1.105-3.343$ & 0.021 \\
\hline HER 2 + & $39(45.9)$ & $46(54.1)$ & & 2.615 & $1.467-4.661$ & 0.001 \\
\hline HR +/HER2- & $62(25.1)$ & 185 (74.9) & & 1 & & \\
\hline $\mathrm{Ki}-67$ index & & & $<0.001$ & & & \\
\hline$\geq 25 \%$ & $123(42.6)$ & $166(57.4)$ & & 2.716 & $1.699-4.340$ & $<0.001$ \\
\hline$<25 \%$ & $44(22.4)$ & $152(77.6)$ & & 1 & & \\
\hline Treatment regimen & & & 0.003 & & & 0.001 \\
\hline CEFci & $73(44.5)$ & $91(55.5)$ & & 2.081 & $1.264-3.427$ & 0.004 \\
\hline EC & $44(27.3)$ & $117(72.7)$ & & 0.821 & $0.489-1.378$ & 0.455 \\
\hline CEF & $50(31.3)$ & $110(68.8)$ & & 1 & & \\
\hline
\end{tabular}

a Measured by ultrasonography

b Include infiltrating lobular carcinoma, medullary carcinoma, colloid carcinoma, metaplastic carcinoma, neuroendocrine carcinoma, cribriform carcinoma, and micropapillary carcinoma

c $I H C$ immunohistochemistry, $H R$ hormone receptor, HER2 human epidermal growth factor receptor 2

d No further assessment of HER2 by fluorescence in situ hybridization (FISH) in 32 HER2 (2+) patients

difference was close to statistical significance $(P=0.059)$. The percentages of patients with thrombocytopenia were $9.1 \%(15 / 164)$ in arm A, including $1.2 \%$ with grade III/ IV; $2.5 \%(4 / 160)$ in arm B; and $7.5 \%(12 / 161)$ in arm C, and the difference was statistically significant $(P=0.040)$. The percentages of patients with ALT/AST $>2.5$ times the institutional UNL were $9.1 \%(15 / 164)$ in arm A, $4.4 \%$ (7/ $160)$ in arm B, and $3.7 \%$ (6/161) in arm C, respectively, and the difference was close to statistical significance $(P=0.073)$.

\section{Discussion}

Clinically, 5-fluorouracil (5-Fu) has been commonly used as a single agent or in combination with other chemotherapies in breast cancer treatment for decades [15-17]. Continuous infusional 5-Fu combined with epirubicin and cisplatin (ECciF) regimen appears to be more active than conventional regimens for both advanced breast cancer and large operable breast cancer, but the contribution of 5-Fu to the anthracycline-cycloph 
Table 4 Hematologic and biochemical toxicity

\begin{tabular}{|c|c|c|c|c|}
\hline Toxicity & $\begin{array}{l}\text { Arm A } \\
\text { CEFci } \\
(N=164) \\
N(\%)\end{array}$ & $\begin{array}{l}\text { Arm B } \\
\text { CEF } \\
(N=160) \\
N(\%)\end{array}$ & $\begin{array}{l}\text { Arm C } \\
\mathrm{EC}(N=161) \\
N(\%)\end{array}$ & $P$ value \\
\hline \multicolumn{5}{|l|}{ Toxicity (grades I-IV) } \\
\hline Neutrophil count & $153(93.3)$ & $148(92.5)$ & $145(90.1)$ & 0.538 \\
\hline Hemoglobin count & $56(34.1)$ & $48(30.0)$ & $36(22.4)$ & 0.059 \\
\hline Platelet count & $15(9.1)$ & $4(2.5)$ & $12(7.5)$ & 0.040 \\
\hline ALT/AST & $49(29.9)$ & $34(21.3)$ & $35(21.7)$ & 0.125 \\
\hline \multicolumn{5}{|c|}{ Toxicity (grades III/IV) } \\
\hline Neutrophilcount & $132(80.5)$ & $119(74.4)$ & $116(72.0)$ & 0.186 \\
\hline Hemoglobin count & $5(3.0)$ & $1(0.6)$ & $1(0.6)$ & 0.106 \\
\hline Platelet count & $2(1.2)$ & $0(0.0)$ & $0(0.0)$ & 0.140 \\
\hline ALT/AST & $15(9.1)$ & $7(4.4)$ & $6(3.7)$ & 0.073 \\
\hline
\end{tabular}

The toxicity is scored according to the CTC common toxicity criteria ALT alanine aminotransferase $A S T$ aspartate aminotransferase osphamide regimens (AC or EC) has not been well defined $[18,19]$.

Our study showed that the outcome of administration of low-dose continuous infusional 5 -Fu $\left(200 \mathrm{mg} / \mathrm{m}^{2}\right) 24 \mathrm{~h}$ daily for 21 days was not superior to that of high-dose intravenous bolus $\left(600 \mathrm{mg} / \mathrm{m}^{2}\right)$ on day 1 , with no statistically significant difference in pathologic complete responses in breast between CEFci arm and CEF arm, although the percentage of patients achieving MP 4/5 response in breast in CEFci arm was almost as twice as that in CEF arm. Compared to the treatment without 5-Fu in the regimen, 5-Fu administrated as intravenous bolus $600 \mathrm{mg} /$ $\mathrm{m}^{2}$ on day 1 did not show any significant advantage of efficacy improvement, with MP 4/5 response rate of $31.3 \%$ in $\mathrm{CEF}$ arm versus $27.3 \%$ in $\mathrm{EC}$ arm. In the TOPIC trial which randomly designed 426 patients with operable breast cancer tumor $\geq 3 \mathrm{~cm}$ to receive six cycles of either epirubicin-cisplatin and continuous infusional 5-Fu (infusional ECisF) or doxorubicin-cyclophosphamide (AC) before surgery to compare the response rates between the two arms [20], no statistically significant differences were observed both in overall response rates (77 vs. $75 \%$, $P=0.6$ ) and in the pCR rates (both $16 \%, P=1.0$ ). The discrepant results between our study and those of the TOPIC trial possibly arise from the different chemotherapeutic agent doses and regimens employed.

In the aspect of hematologic toxicity, no statistically significant differences were observed in the incidences of grade III/IV neutropenia among the three arms in our study (80.5, 74.4, and $72.0 \%$, respectively, $P=0.538)$, but thrombocytopenia and decreased hemoglobin appeared to be observed more in CEFci arm compared with the other two arms, with differences being statistically significant or close to statistical significance $(P=0.040$, and 0.059 , respectively). In terms of biochemical toxicity, however, elevated aminotransferase occurred in $9.1 \%$ of patients receiving CEFci regimen, which is higher than $4.4 \%$ with $\mathrm{CEF}$ regimen and $3.7 \%$ with EC regimen, and the difference was close to statistical significance $(P=0.073)$.

It is noteworthy that nine patients in CEFci arm rejected the protocols after randomization and before the beginning of the first cycle of chemotherapy, since they were worried that their daily life would be influenced by probable inconvenience of continuous infusional 5-Fu and periodic maintenance of central venous catheters. Similarly, three patients refused continuous infusional 5-Fu during the process of treatment, and ci 5-Fu was ceased in another seven patients after the removal of catheters due to catheter-related events, such as thrombus and infection. However, treatment plans were changed apparently more frequently in patients receiving $\mathrm{EC}$ or $\mathrm{CEF}$ regimen according to tumor response assessed by ultrasonography after completion of two or four cycles of neoadjuvant chemotherapy, and 25 patients with SD or PD received either four cycles of paclitaxel chemotherapy or endocrinotherapy, or underwent surgery immediately according to physician's decisions and/or patient's wills.

To our knowledge, this is the only randomized controlled clinical study comparing the efficacy and safety aspects of different anthracycline-based regimens in primary breast cancer neoadjuvant chemotherapy between standard epirubicin-cyclophosphamide (EC) regimen and EC combined with $5-\mathrm{Fu}$, as well as between continuous infusion and intravenous bolus as two different administration approaches of 5-Fu.

In conclusion, although this study shows that there are no statistically significant differences in pCR rates among the three arms, the potential advantage of the 
administration of low-dose continuous infusional 5-Fu in improving the efficacy of anthracycline-based chemotherapy still requires further research. However, the accompanied hematologic and biochemical toxicities, catheterrelated complications, and poor compliance with inconvenient daily life should also be noted in patients receiving the CEFci regimen.

Acknowledgments The authors would like to acknowledge all the nurses in the breast center for their services, and women involved in this study.

Funding This study was supported by graunts from Beijing Science $\&$ technique committee priority project (D09050703570904)

\section{Compliance with ethical standards}

Conflict of interest The authors declare that they have no conflict of interest.

Ethical standard This study complies with current Chinese law.

Open Access This article is distributed under the terms of the Creative Commons Attribution-NonCommercial 4.0 International License (http://creativecommons.org/licenses/by-nc/4.0/), which permits any noncommercial use, distribution, and reproduction in any medium, provided you give appropriate credit to the original author(s) and the source, provide a link to the Creative Commons license, and indicate if changes were made.

\section{References}

1. Iqbal J, Shafi AA, Alharthi BN (2014) Neoadjuvant chemotherapy in locally advanced breast cancer. J Coll Phys Surg Pak 24(11):845-848

2. Caudle AS, Kuerer HM (2014) Breast conservation therapy after neoadjuvant chemotherapy: optimization of a multimodality approach. J Surg Oncol 110(1):32-36

3. Read RL, Flitcroft K, Snook KL, Boyle FM, Spillane AJ (2015) Utility of neoadjuvant chemotherapy in the treatment of operable breast cancer. ANZ J Surg 85(5):315-320

4. Berruti A, Amoroso V, Gallo F, Bertaglia V, Simoncini E, Pedersini R, Ferrari L, Bottini A, Bruzzi P, Sormani MP (2014) Pathologic complete response as a potential surrogate for the clinical outcome in patients with breast cancer after neoadjuvant therapy: a meta-regression of 29 randomized prospective studies. J Clin Oncol 32(34):3883-3891

5. Wang-Lopez Q, Chalabi N, Abrial C, Radosevic-Robin N, Durando X, Mouret-Reynier MA, Benmammar KE, Kullab S, Bahadoor M, Chollet P et al (2015) Can pathologic complete response ( $\mathrm{pCR}$ ) be used as a surrogate marker of survival after neoadjuvant therapy for breast cancer? Crit Rev Oncol Hematol 95(1):88-104

6. Adlard JW, Dodwell DJ (2001) Optimum anthracycline-based chemotherapy for early breast cancer. Lancet Oncol 2(8):469-474

7. Sirohi B, A'Hern R, Coombes G, Bliss JM, Hickish T, Perren T, Crawford M, O'Brien M, Iveson T, Ebbs S et al (2010) A randomised comparative trial of infusional ECisF versus conventional FEC as adjuvant chemotherapy in early breast cancer: the TRAFIC trial. Ann Oncol 21(8):1623-1629

8. Del Mastro L, De Placido S, Bruzzi P, De Laurentiis M, Boni C, Cavazzini G, Durando A, Turletti A, Nisticò C, Valle E et al (2015) Fluorouracil and dose-dense chemotherapy in adjuvant treatment of patients with early-stage breast cancer: an openlabel, $2 \times 2$ factorial, randomised phase 3 trial. Lancet 385(9980): 1863-1872

9. Nolè F, Munzone E, Mandalà M, Catania C, Orlando L, Zampino MG, Minchella I, Colleoni M, Peruzzotti G, Marrocco E et al (2001) Vinorelbine, cisplatin and continuous infusion of 5-fluorouracil (ViFuP) in metastatic breast cancer patients: a phase II study. Ann Oncol 12(1):95-100

10. Regierer AC, Reinecke F, Weigel A, Dieing A, LehenbauerDehm S, Schwarzlose-Schwarck S, Possinger K, Eucker J (2011) $5 \mathrm{FU}$ continuous infusion in heavily pretreated advanced breast cancer patients. Onkologie 34(12):696-700

11. Goldhirsch A, Wood WC, Coates AS, Gelber RD, Thürlimann B, Senn HJ, Panel members (2011) Strategies for subtypes-dealing with the diversity of breast cancer: highlights of the St. Gallen International Expert Consensus on the Primary Therapy of Early Breast Cancer. Ann Oncol 22(8):1736-1747

12. Yang WT, Dryden MJ, Gwyn K, Whitman GJ, Theriault R (2006) Imaging of breast cancer diagnosed and treated with chemotherapy during pregnancy. Radiology 239(1):52-60

13. Ogston KN, Miller ID, Payne S, Hutcheon AW, Sarkar TK, Smith I, Schofield A, Heys SD (2003) A new histological grading system to assess response of breast cancers to primary chemotherapy: prognostic significance and survival. Breast 12(5):320-327

14. Qi M, Li JF, Xie YT, Lu AP, Lin BY, Ouyang T (2010) Weekly paclitaxel improved pathologic response of primary chemotherapy compared with standard 3 weeks schedule in primary breast cancer. Breast Cancer Res Treat 123(1):197-202

15. Smith IE (1996) Continuous infusional 5-fluorouracil in breast cancer or the revival of an old drug? Ann Oncol 7(8):771-772

16. O'Byrne KJ, Koukourakis MI, Saunders MP, Salisbury AJ, Isaacs R, Varcoe S, Taylor M, Ganesan TS, Harris AL, Talbot DC (1998) Cyclophosphamide, methotrexate and infusional 5-fluorouracil (infusional CMF) in metastatic breast cancer. Br J Cancer 77(11):1950-1956

17. Stuart NS, Mclllmurray MB, Bishop JL, Johnston SR, Price CG, O'Reilly SM, Joffe JK, Neave F, Whipp EC (2008) Vinorelbine and infusional 5-fluorouracil in anthracycline and taxane pretreated metastatic breast cancer. R Coll Radiol 20(2):152-156

18. Smith IE, Walsh G, Jones A, Prendiville J, Johnston S, Gusterson B, Ramage F, Robertshaw H, Sacks N, Ebbs S et al (1995) High complete remission rates with primary neoadjuvant infusional chemotherapy for large early breast cancer. J Clin Oncol 13(2):424-429

19. Jones AL, Smith IE, O'Brien ME, Talbot D, Walsh G, Ramage F, Robertshaw H, Ashley S (1994) Phase II study of continuous infusion fluorouracil with epirubicin and cisplatin in patients with metastatic and locally advanced breast cancer: an active new regimen. J Clin Oncol 12(6):1259-1265

20. Smith IE, A'Hern RP, Coombes GA, Howell A, Ebbs SR, Hickish TF, O'Brien ME, Mansi JL, Wilson CB, Robinson AC et al (2004) A novel continuous infusional 5-fluorouracil-based chemotherapy regimen compared with conventional chemotherapy in the neo-adjuvant treatment of early breast cancer: 5 year results of the TOPIC trial. Ann Oncol 15(5):751-758 